\title{
Flipped Classroom-Based Foreign Language Teaching Research Abroad: A Review
}

\author{
Ling Ding \\ School of Foreign Studies, Nanjing University of Posts and Telecommunications, Nanjing 210023, \\ China \\ lyinding@163.com
}

\begin{abstract}
This paper provides a comprehensive review and analysis of the research into the flipped classroom-based foreign language teaching abroad from the four perspectives of general research trends, research foundation, research hotspots, priorities and trends, and research results and reflection and research methods, based on the research papers published abroad from the year 2012 to 2018, with the help of the method of Citespace visual analysis and manual statistics. The results indicate that: 1) At present, researches in this field is increasing, and the basic researches are mostly from other disciplines; 2) The research focus and key points in this field include four aspects: teacher education, professional purpose, oral expression and technical equipment acceptance; 3) From the content of the research, the researchers use experimental and contrasting methods to explore the application of the flipped classroom in foreign language teaching from the experience and feelings of the students; 4) Most of the research results prove the positive influence of the flipped classroom on promoting foreign language teaching, but there are still some studies that question the promotion efficiency of the flipped classroom; 5) Empirical research far outweighs theoretical research in research nature and methodologies, and it shows a trend of cross-domain integration with brain science research. Based on the analytical results, the paper discusses the limitations of the foreign research on the flipped classroom-based foreign language teaching, and proposes directions and prospects for its future development.
\end{abstract}

Keywords: Flipped Classroom, Foreign Language Research, Review and Prospects.

\section{Introduction}

Flipped Classroom or Inverted Classroom is a hybrid teaching model based on computer technology. It was sprouted in 1997 by Eric Mazur's "Peer Teaching Method" [1]. However, it was not until 2000 that the academic community proposed the concept of "flipped classroom" [2, 3]. Among them, Lage paid attention to the description of the application process of the flipped classroom in a specific course, and Wesley Shell (2000) outlined the model framework of the flipped classroom as a whole. But their results have not caused widespread concern in the academic world.

The International Open Education Resource Movement (OER) and the establishment of teaching resources sharing platform (YouTube, which was born in 2005, and the Khan Academy, which was founded in 2007), have provided favorable conditions for the use of flippped classrooms in teaching. In 2007, two American teachers, Aaron Sams and Jonathan Bergnann, successfully applied "flipped classroom" to chemistry teaching [4]. Until 2012, the flippped classroom was applied to English language teaching [5].

This paper intends to sort out the literature on college English teaching researches on flipped classroom from 2013 to 2018, and try to use quantitative and qualitative methods to analyses the overall trend of research, literature co-citation analysis, research hotspots, key points and trends, and the nature of researches. On this basis, this paper reflects on the limitations of research in this field, and looks forward to the future development of this field.

\section{Research Trends}

This study uses the collection of Web of Science core collection database as the source of the literature. The search condition is "Flipped classroom" AND Language learning. The search period is 2012-2018. After manually removing the irrelevant documents, the results are obtained. There are 
98 articles in journals and 217 papers in conference papers. The statistics of the two types of documents are statistically analyzed, and the development trend is shown in Fig.1.

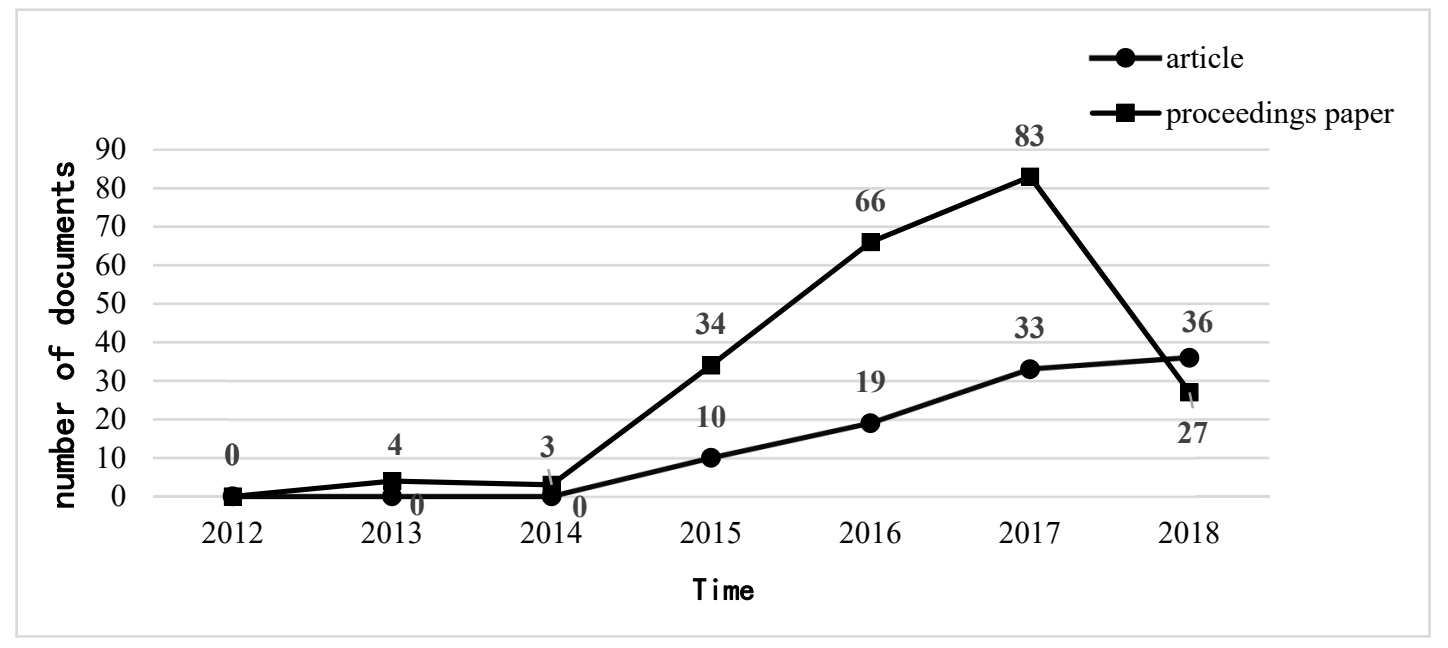

Fig. 1 Research trends

The Fig. 1 shows that foreign language teaching based on flipping classrooms can be roughly divided into three stages: 2012-2014 is the germination period of the research. During this period, the research results are rare, and most of them are published in the form of conference papers. The development period of the research is from 2014 to 2017, the number of documents has grown rapidly and the results are fruitful. 2017-2018 is the gradual period of this field. Although the number of journal articles has increased slightly, the number of conference documents has dropped significantly. To a certain extent, this phenomenon reflects a decline in the researches in this field.

\section{Research Hotspots, Priorities and Trends}

In this paper, Citespace software was used to analyze the co-occurrence of terms in 98 foreign journal articles. After the clustering of the topic network (the cluster name is extracted from the title), four clustering labels are shown in Fig.2.

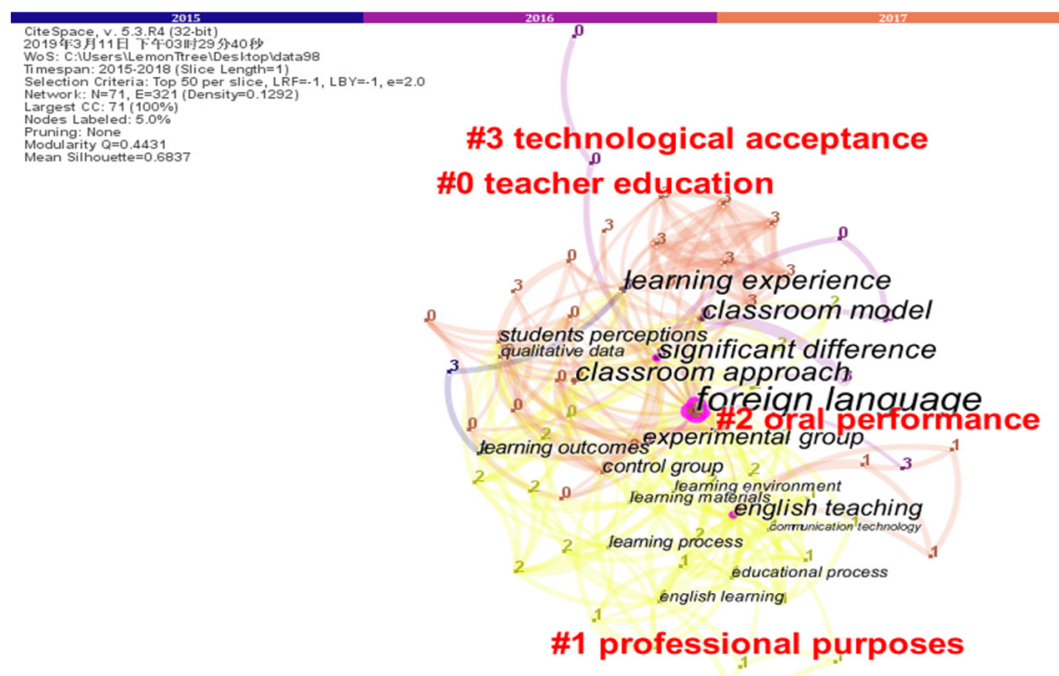

Fig. 2 Terms co-occurrence network

From the perspective of clustering, the current research is divided into four areas, namely, teacher education, professional purposes, oral performance, and technological acceptance. 
Cluster 0 includes pre-service English teacher, teachers training, participation rate cognitive processing, complex cognitive skill, et., al. The connotation of this cluster is to emphasize the importance of teacher training, and reflects the professional quality of teachers and the role of teacher role change in the construction of flipped classrooms.

Cluster 1 includes English for specific purposes, professional competences, integration courses, and project-based teaching, et., al. This clustering indicates that foreign language teaching based on flipped classrooms is based on the professional development of students, and helps them improve their professional competitiveness through language learning (especially English).

Cluster 2 includes teaching Chinese oral presentation, oral interpretation and other words, et.,al. These words show that flipped classrooms are often used to improve learners' speaking ability, especially to improve spoken English and Chinese.

Cluster 3 includes bringing your own device, clicker system, online learning community, and technology acceptance model (TAM). This clustering and related words exemplify another research trend in this field: using technology acceptance models to explore language learners' acceptance of technology.

\section{Research Results and Reflection}

This study combines the above Citespace analysis results and the critical reading of the literature to explain its research results, and find out the problems and deficiencies of the current research.

Through analysis, it is found that there is still some controversy about the promotion efficiency of flipped classrooms. Most of the researches mainly reflect the ability of flipped classroom promotion through grade changes and student evaluation, but such evaluation is too simple and subjective. Future researchers can conduct related research in a comparative study. There are many factors that influence the effect of foreign language flipped classroom teaching. From the current research results, the use of teaching technologies in the flipping classroom essentially help teachers to create an open and independent communication and learning environment [6], so that students can learn actively. Therefore, the exploration of active learning is the key to research, and technical tools are only an aid. We can see the inevitable trend of foreign language education informationization. But at the same time, we should also clearly understand that technological development is a double-edged sword. We cannot amplify its role without any scientific proof and blindly pursue it. The teachers and students' adaptability to new technologies is also needed to be continuously strengthened. The cultivation of information technology literacy is also an important aspect of flipped foreign language teaching.

\section{References}

[1]. Mazur, E. \& Somers, M. D. Peer instruction: a user's manual [J]. Physics Today, 1997(4): 6869.

[2]. Lage, M. J., Platt, G. J. \& Treglia, M. Inverting the classroom: A gateway to creating an inclusive learning environment [J]. Journal of Economic Education, 2000 (1): 30-43.

[3]. Baker, J. W. The 'classroom flip': using web course management tools to become the guide on the side [C]// Proceedings of the 11th International Conference on College Teaching and Learning, 2000: 9-17.

[4]. Bergmann, J. \& Sams, A. Remixing chemistry class [J]. Learning and Leading with Technology, 2008(4): 22-27.

[5]. Basal, A. "The use of flipped classroom in foreign language teaching" [C]// Proceedings of the 3rd Black Sea ELT Conference Technology: A Bridge to Language Learning, 2012: 8-12.

[6]. Mehring, J. Present Research on the Flipped Classroom and Potential Tools for the EFL Classroom[J]. Computers in the Schools, 2016(1):1-10. 